\title{
Adsorption of Cd(II) on Zn-Al LDHs (Layered Double Hydroxides) Intercalated with Chelating Agents EDTA
}

\author{
Shuang Zhang ${ }^{1}$, Naoki Kano $^{2 *}$ and Hiroshi Imaizumi ${ }^{2}$ \\ 1. Graduate School of Science and Technology, Niigata Univ., Niigata, Japan \\ 2. Dept. of Chem. and Chem. Eng., Fac. of Eng., Niigata Univ., Niigata, Japan
}

\begin{abstract}
The hydrotalcite-like compound $\left[\mathrm{Zn}_{2} \mathrm{Al}(\mathrm{OH})_{6}\right] \mathrm{NO}_{3} \cdot \mathrm{mH}_{2} \mathrm{O}$ (shorted as $\mathrm{ZnAl}-\mathrm{NO}_{3}$ ) was intercalated with the chelating agent EDTA (ethylene diamine tetraacetic acid) by anion exchange to uptake cadmium ion from aqueous solutions. The materials synthesized in this work were characterized by chemical analysis, FT-IR (fourier transform infrared spectroscopy), XRD (X-ray powder diffraction) to confirm their properties. In order to investigate the optimum conditions for $\mathrm{Cd}(\mathrm{II})$ adsorption, the amount of Cd(II) adsorbed by Zn-Al LDHs intercalated with EDTA (ZnAl-EDTA) under different conditions (i.e., adsorbent dosage, temperature and contact time) were determined by ICP-AES (inductively coupled plasma-atomic emission spectrometry). Adsorption isotherms of $\mathrm{Cd}$ (II) onto ZnAl-EDTA were measured at varying initial Cd concentrations $(0.05 \mathrm{mg} / \mathrm{L}$ to $1 \mathrm{mg} / \mathrm{L}) \mathrm{under}$ optimized conditions. The data were applied to Langmuir and Freundlich isotherms model, and well fitted by the Freundlich isotherms model. The pseudo-second-order kinetic model was more adequate to describe the kinetic in this case.
\end{abstract}

Key words: Layered Double Hydroxide, EDTA, cadmium, adsorption, kinetic.

\section{Introduction}

Recently, heavy metal contamination is a widespread environmental problem which can pose serious threats to human and environment. Their bioacumulation make them have high toxicity, and most of them have no biodegradable [1]. $\mathrm{Cd}$ (Cadmium) is one of extremely toxic metal which commonly found in industrial places such as batteries and electroplating industry. The drinking water guideline value in WHO for $\mathrm{Cd}$ is $0.003 \mathrm{mg} / \mathrm{L}$. For human, extended exposure by $\mathrm{Cd}$ can lead to the damage for mental and central nervous function, blood composition, bone, liver and other vital organs [2, 3]. Thus the treatment of waste water including $\mathrm{Cd}$ has become a hot topic of environment science and technology $[4,5]$.

There are several methods to remove metal ions in aqueous solutions. Metal ions can interact with solid surface in many ways including precipitation,

\footnotetext{
*Corresponding author: Naoki KANO, Ph.D., research fields: environmental chemistry and environmental preservation.
}

adsorption, ion exchange. One effective way of removing metals is adsorption on various materials such as activated carbon, biomaterials and clay minerals [6-8].

LDHs (Layered Double Hydroxides) are typical intercalation compounds with the general formula $\left[\mathrm{M}^{\mathrm{II}}{ }_{1-\mathrm{x}} \mathrm{M}^{\mathrm{III}}(\mathrm{OH})_{2}\right]\left(\mathrm{A}^{\mathrm{n}-}\right)_{\mathrm{x} / \mathrm{n}} \cdot \mathrm{mH}_{2} \mathrm{O}$, where $\mathrm{M}^{\mathrm{II}}$ and $\mathrm{M}^{\mathrm{III}}$ are divalent and trivalent metals, $\mathrm{A}^{\mathrm{n}-}$ denotes compensating for the positive charger of the metal hydroxide layers. The structure and their high anionic exchange capacity make LDHs suitable for many applications including pollutant sorbents, catalysts and anionic exchangers $[9,10]$.

Considering the structure of LDHs, it is suggested that these materials can be intercalated easily with with other anions. LDHs modified with chelating agents as the potential adsorbents of heavy metals from the aqueous solution has been also studied [2, 11, 12]. The potential adsorbents for these compounds may be due to the stability of the chelates formed between ligands and metals. The aim of this work is at first to synthesize and to characterize LDHs intercalated with 
the typical chelating agents EDTA (ethylene diamine tetraacetic acid), and to study the uptake of Cd(II) by these hybrid compounds for investigating the efficiency of LDHs intercalated with EDTA as adsorbent for $\mathrm{Cd}(\mathrm{II})$ for more practical use in future. Furthermore, kinetic and thermodynamic analyses on adsorption of $\mathrm{Cd}$ by LDHs intercalated with EDTA were also conducted to survey the mechanism of adsorption process.

\section{Experiments}

\subsection{Materials and Reagents}

Chemical reagents including $\mathrm{Zn}\left(\mathrm{NO}_{3}\right)_{2} \cdot 6 \mathrm{H}_{2} \mathrm{O}$, $\mathrm{Al}\left(\mathrm{NO}_{3}\right)_{3} \cdot 9 \mathrm{H}_{2} \mathrm{O}, \quad \mathrm{NaOH}, \quad \mathrm{Na}_{2} \mathrm{H}_{2}$ EDTA $2 \mathrm{H}_{2} \mathrm{O}$ were purchased from Kanto Chemical Co., Inc., and all reagents used were of analytical grade. $\mathrm{CO}_{2}$ free water ( $>18.2 \mathrm{M} \Omega$ ) which was treated by an ultrapure water system (RFU 424TA, Advantech Aquarius) was employed throughout the work. Cd(II) standard solutions were prepared by diluting a standard solution $(1,000 \mathrm{mg} / \mathrm{L})$.

\subsection{Synthesis of the Adsorbents}

The synthesis of ZnAl-EDTA includes two steps: the preparation of the precursor $\left(\mathrm{ZnAl}-\mathrm{NO}_{3}\right)$ and the anion-exchange reaction of this compound with $\mathrm{Na}_{2} \mathrm{H}_{2}$ EDTA [13]. All the synthesis were purged with $\mathrm{N}_{2}$ to avoid $\mathrm{CO}_{2}$ uptake from atmosphere.

\subsubsection{Synthesis of $\mathrm{ZnAl}-\mathrm{NO}_{3}$}

The $\mathrm{ZnAl}-\mathrm{NO}_{3}$ was prepared by dropping addition of a $100 \mathrm{~mL}$ aqueous solution of $0.02 \mathrm{~mol} \cdot \mathrm{L}^{-1}$ $\mathrm{Zn}\left(\mathrm{NO}_{3}\right)_{2} \cdot 6 \mathrm{H}_{2} \mathrm{O}$ and $0.01 \mathrm{~mol} \cdot \mathrm{L}^{-1} \mathrm{Al}\left(\mathrm{NO}_{3}\right)_{3} \cdot 9 \mathrm{H}_{2} \mathrm{O}$ to a $100 \mathrm{~mL} \mathrm{NaOH}$ solution. Then, the solutions were agitated at $70{ }^{\circ} \mathrm{C}$ for $8 \mathrm{~h}$, separated by centrifugation and washed until neutral $[14,15]$.

\subsubsection{Synthesis of ZnAl-EDTA}

The ZnAl-EDTA was synthesized as follows. Under a $\mathrm{N}_{2}$ atmosphere, $0.015 \mathrm{~mol}$ of $\mathrm{Na}_{2} \mathrm{H}_{2}$ EDTA $2 \mathrm{H}_{2} \mathrm{O}$ was added to the $150 \mathrm{~mL}$ of suspended solution of $\mathrm{ZnAl}-\mathrm{NO}_{3}$. Then, the mixing solutions were agitated at $70{ }^{\circ} \mathrm{C}$ for $8 \mathrm{~h}$, separated by centrifugation, washed until neutral and then dried at $60{ }^{\circ} \mathrm{C}$ overnight $[11,16]$.

\subsection{Characterization of These Adsorbents}

Elemental chemical analyses of $\mathrm{C}, \mathrm{H}$ and $\mathrm{N}$ were carried out using an elemental analyzer instrument (JMC10, J-SCIENCE LAB CO., Ltd.). Infrared spectra were obtained using the $\mathrm{KBr}$ disc method, with wavenumbers from $400 \mathrm{~cm}^{-1}$ to $4,000 \mathrm{~cm}^{-1}$ on a FT-IR (fourier transform infrared spectroscopy) (Spectrum One, Perkin Elmer Inc.). XRD (X-ray powder diffraction) of powder samples were carried out on a RINT2500HR-PC (RIGAKU Corporation) using $\mathrm{Cu} \mathrm{K} \alpha$ radiation in the scanning range of $2-80^{\circ}$.

\subsection{Adsorption Experiments}

The adsorption experiments of $\mathrm{Cd}(\mathrm{II})$ using $\mathrm{ZnAl}-\mathrm{NO}_{3}$ and ZnAl-EDTA were carried out. A certain amount of $\mathrm{ZnAl}-\mathrm{NO}_{3}$ or ZnAl-EDTA were contacted with $30 \mathrm{~mL}$ of an aqueous solution containing known initial Cd(II) ranging from $0.05 \mathrm{mg} / \mathrm{L}$ to $1 \mathrm{mg} / \mathrm{L}$. Sorption experiments were conducted from $30 \mathrm{~min}$ to $8 \mathrm{~h}$, temperature from $25^{\circ} \mathrm{C}$ to $40{ }^{\circ} \mathrm{C}$. The experiment using $\mathrm{Cd}(\mathrm{II})$ solution without the adsorbent was also performed to identify potential loss of $\mathrm{Cd}$ ion by process such as precipitation.

Following each sorption experiment, the suspension containing the adsorbent and solution including $\mathrm{Cd}$ was filtered through a $0.10 \mu \mathrm{m}$ membrane filter (Mixed Cellulose Ester $47 \mathrm{~mm}$, Advantec MFS, Inc.) to remove $\mathrm{Cd}$ ion that has been adsorbed into the adsorbent. Then, the concentration of $\mathrm{Cd}(\mathrm{II})$ in the filtrate was determined by ICP-AES (inductively coupled plasma atomic emission spectrophotometer) (SPS 1500, Seiko Instrument Inc.).

The Cd(II) uptake by each adsorbent was calculated using Eq. (1):

$$
q=\frac{\left(C_{0}-C_{e}\right)}{W} \cdot V \quad\left[\mu \mathrm{g} \cdot \mathrm{g}^{-1}\right]
$$

where, $q$ is the adsorption capacities of $\mathrm{Cd}(\mathrm{II})$ using $\mathrm{ZnAl}-\mathrm{NO}_{3}$ or $\mathrm{ZnAl}-\mathrm{EDTA}$ at equilibrium $\left(\mu \mathrm{g} \cdot \mathrm{g}^{-1}\right), C_{0}$ 
and $C_{e}$ are the initial and equilibrium concentrations of $\mathrm{Cd}(\mathrm{II})$ in a batch system respectively $\left(\mu \mathrm{g} \cdot \mathrm{L}^{-1}\right), V$ is the volume of the solution (L), and $W$ is the weight of each adsorbent $(\mathrm{g})[17,18]$.

\subsection{Adsorption Isotherms Model}

Adsorption isotherms of adsorption data were studied at varying initial concentration of $\mathrm{Cd}$ (II) from $0.05 \mathrm{mg} / \mathrm{L}$ to $1 \mathrm{mg} / \mathrm{L}$ under optimized conditions of contact time and the dosage of adsorbents in this work.

Based on other previous study [19], two common adsorption models, Langmuir and Freundlich isotherm models were applied to evaluate the adsorption data obtained for $\mathrm{Cd}(\mathrm{II})$.

Langmuir model is given by Eq. (2):

$$
\frac{C_{e}}{q_{e}}=\frac{C_{e}}{q_{\max }}+\frac{1}{K_{L} q_{\max }}
$$

where, $q_{e}$ and $q_{\max }$ are the amount of $\mathrm{Cd}(\mathrm{II})$ at equilibrium and maximum adsorption capacity on the monolayer coverage $\left(\mu \mathrm{g} \cdot \mathrm{g}^{-1}\right)$, respectively and

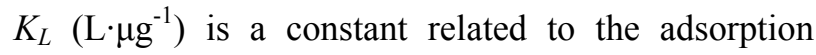
energy.

The linearized Freundlich model isotherm is represented by the Eq. (3):

$$
\log _{10} q_{e}=\log _{10} K_{F}+\left(\frac{1}{n}\right) \log _{10} C_{e}
$$

where, $K_{F}$ and $1 / n$ indicate the adsorption capacity and the adsorption intensity of the system, respectively. The plots of $q_{e}$ versus $C_{e}$ in $\log$ scale can be plotted to determine values of $1 / n$ and $K_{F}$ depicting the constants of Freundlich model $[17,19,20]$.

\subsection{Kinetic Studies}

Kinetic models have been proposed to determine the mechanism of the adsorption process, which provide useful data to improve the efficiency of the adsorption and feasibility of process scale-up. In this study, the adsorption process was studied by fitting pseudo first-order and second-order reactions to the experimental data.

The pseudo first-order model is expressed as the Eq. (4):

$$
\ln \left(q_{e}-q_{t}\right)=\ln q_{e}-k_{1} t
$$

where, $q_{e}$ and $q_{t}$ are the adsorption capacities of Cd(II) at equilibrium and time $t$, respectively $\left(\mu \mathrm{g} \cdot \mathrm{g}^{-1}\right)$, and $k_{1}$ is the rate constant of the pseudo-first-order adsorption $\left(\mathrm{h}^{-1}\right)$.

The linear form of the pseudo second-order rate Eq. (5) is given:

$$
\frac{t}{q_{t}}=\frac{1}{k_{2} q_{e}^{2}}+\frac{t}{q_{e}}
$$

where, $k_{2}$ is the rate constant of the pseudo-second-order adsorption $\left(\mathrm{g} \cdot \mu \mathrm{g}^{-1} \cdot \mathrm{h}^{-1}\right)[17,20]$.

\section{Results and Discussions}

\subsection{Synthesis and Characterization of $L D H$}

The chemical analysis of LDHs samples is shown in Table 1. The molar ratio of $\mathrm{Zn} / \mathrm{Al}$ (2.01) in $\mathrm{ZnAl}-\mathrm{NO}_{3}$ is well fitted with the expected formula. However, the ZnAl-EDTA has lower $\mathrm{Zn} / \mathrm{Al}$ ratios than precursor $\mathrm{LDH}$.

The decrease suggests $\mathrm{Zn}(\mathrm{OH})_{2}$ octahedron in hydroxyl layer has a partial dissolution (pKsp $\left(\mathrm{Zn}(\mathrm{OH})_{2)}=13.7, \mathrm{pKsp}\left(\mathrm{Al}(\mathrm{OH})_{3}\right)=32.7\right)$ during the anion exchange reaction which is performed at $\mathrm{pH}$ 5-6. Moreover, because of the stability constants of Zn-EDTA complexes and Al-EDTA complexes are 16.5 and 16.1, respectively, the presence of polidentate ligand also can result in this decrease $[11,16,21]$. While the $\mathrm{C} / \mathrm{N}$ ratio (4.35) is similar to that of EDTA ligand (5), the little gap between them is mainly due to the registration of nitrate ions in the interlayer [19].

The FT-IR spectra of $\mathrm{ZnAl}^{-\mathrm{NO}_{3}}$ and ZnAl-EDTA are shown in Fig. 1. Both Fig. 1(a) and Fig. 1(b) show typical $-\mathrm{OH}$ vibration modes due to the hydroxide layer between $400 \mathrm{~cm}^{-1}$ and $1,000 \mathrm{~cm}^{-1}$ [22]. 
Table 1 Chemical analysis of LDHs synthesized in this work.

\begin{tabular}{lcllllcl}
\hline & \multicolumn{4}{c}{ w t $\%$} & \multicolumn{5}{c}{ Atomic ratios } & Proposed formula \\
\cline { 2 - 8 } & $\mathrm{C}$ & $\mathrm{N}$ & $\mathrm{H}$ & $\mathrm{M}^{\mathrm{II}} / \mathrm{M}^{\mathrm{III}}$ & $\mathrm{C} / \mathrm{N}$ & $\mathrm{H} / \mathrm{N}$ & \\
\hline${\mathrm{ZnAl}-\mathrm{NO}_{3}}$ & 0.06 & 4.26 & 2.38 & 2.10 & 0.00 & 5.72 & {$\left[\mathrm{Zn}_{2} \mathrm{Al}(\mathrm{OH})_{6}\right] \mathrm{NO}_{3}$} \\
ZnAl-EDTA & 13.4 & 3.08 & 3.60 & 0.97 & 4.35 & 10.6 & {$\left[\mathrm{Zn}_{2} \mathrm{Al}(\mathrm{OH})_{6}\right]_{2}\left[\mathrm{C}_{10} \mathrm{H}_{14} \mathrm{~N}_{2} 0_{8}\right]$} \\
\hline
\end{tabular}

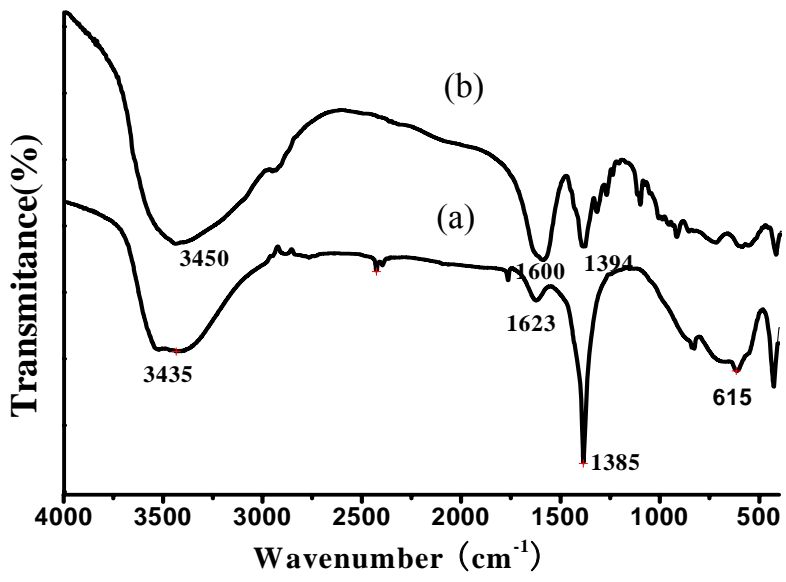

Fig. 1 FT-IR spectrum of sample (a) $\mathrm{ZnAl}^{-N}$; (b) ZnAl-EDTA.

The very sharp peak at $1,385 \mathrm{~cm}^{-1}$ in Fig.1(a) is attributed to the $\mathrm{NO}_{3}$ stretching vibration. The $\mathrm{NO}_{3}$ stretching vibration at $1,385 \mathrm{~cm}^{-1}$ is not observed from Fig. 1(b). It may be because the group is hidden by the band at $1,394 \mathrm{~cm}^{-1}[19,20]$. The absorption bands at $1,600 \mathrm{~cm}^{-1}$ and $1,394 \mathrm{~cm}^{-1}$ are characteristic of the symmetrical and asymmetrical vibration of COO- groups. The position of these bonds in Fig. 1 is similar to that in the spectrum of $\mathrm{ZnAl}-\mathrm{NO}_{3}$ and ZnAl-EDTA which is reported by Park et al. [23, 24]. It is found that EDTA has been intercalated into the interlayer successfully, although a certain amount of $-\mathrm{NO}_{3}$ may be retained in the compound based on the chemically analysis results. The broad band at around $3,450 \mathrm{~cm}^{-1}$ is attributed to the $-\mathrm{H}$ bonding stretching vibrations of $-\mathrm{OH}$ groups in the brucite like layer and water molecule, and the band at $1,623 \mathrm{~cm}^{-1}$ of Fig. 1(a) is assigned to water bending vibration [4, 19].

XRD patterns of $\mathrm{ZnAl}-\mathrm{NO}_{3}$ and $\mathrm{ZnAl}-\mathrm{EDTA}$ are shown in Fig. 2. Both Fig. 2(a) and (b) are typical XRD patterns of $\mathrm{LDH}$. The strong diffraction peaks at low angle due to basal planes (003), (006), (009) were sharp and symmetric compared to the peaks at high angle, which are characteristic of clay minerals having a layered structure [23-25].

From the XRD pattern, the basal spacing $(d)$ of sample were calculated by using Bragg equation $(2 d \sin \theta=n \lambda ; \lambda$ : wavelength) and the angle $(\theta)$ of peak (003). Then the gallery height are obtained by subtraction from the basal spacing to the layer width $(0.48 \mathrm{~nm})$ [24].

The basal spacing values of (a) $\mathrm{ZnAl}-\mathrm{NO}_{3}$ and (b) ZnAl-EDTA were about $0.89 \mathrm{~nm}$ and $1.47 \mathrm{~nm}$, respectively, and the gallery height were $0.41 \mathrm{~nm}$ and $0.99 \mathrm{~nm}$. It indicates that the intercalation of EDTA into $\mathrm{ZnAl}-\mathrm{NO}_{3}$ gives rise to an increase in the basal spacing and the gallery height. The value is estimated for modified $\mathrm{LDH}$, and it is closely agreement with the dimensions of previous EDTA complexes (0.9-1 nm) observed in single crystal XRD of M-EDTA (M: metal) compound $[4,11,17,19]$.

\subsection{Adsorption Experiments}

The effect of contact time on the adsorption is shown in Fig. 3. Based on the previous studies of ZnAl-EDTA [2], the increased removal of heavy

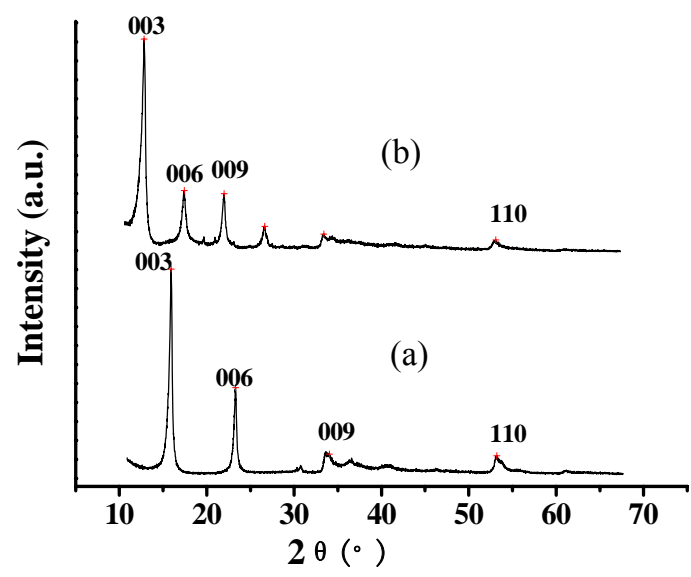

Fig. 2 XRD of sample (a) $\mathrm{ZnAl}-\mathrm{NO}_{3}$; (b) ZnAl-EDTA. 


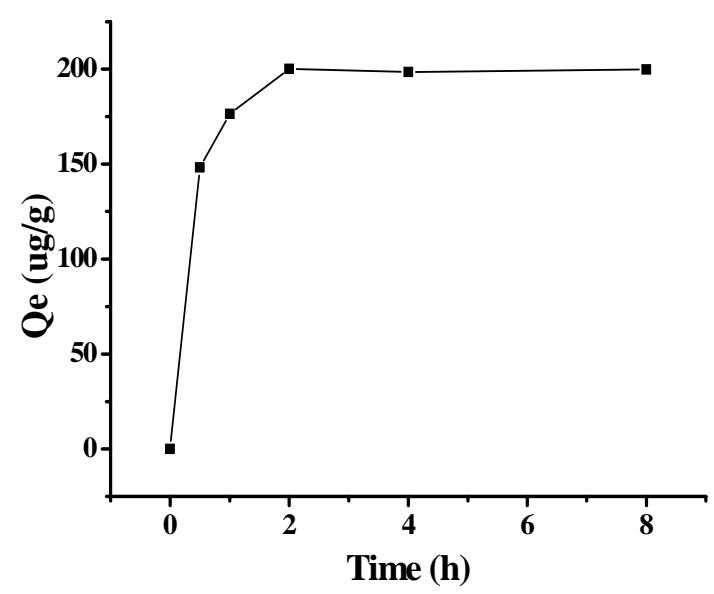

Fig. 3 Effect of time on adsorption of $\mathrm{Cd}(\mathrm{II})$ onto ZnAl-EDTA.

metal cation is produced by three parts: an exchange reaction of chelated zinc and heavy metal cation; the reaction of heavy metal cation with EDTA ions in the interlayer; and the metal cation hydroxide precipitation occurred at higher $\mathrm{pH}$. As the first two reactions both occur when the adsorbent was added in the solution, these two reactions are not distinguishable during the adsorption process.

From the chemical analysis of samples, it is suggested that the chelated zinc was released into the solution when the adsorbent was dispersed in the solution. Then the chelated zinc may be consumed by reacting with $\mathrm{Cd}(\mathrm{II})$ in aqueous solution. However, the presence of chelated zinc does not affect the adsorption process in this case, because the stability constants of Zn-EDTA complexes and Cd-EDTA complexes are both about 16.5 . The fast removal rate in the beginning may be attributable to more available sites at the initial stage $[21,26]$.

The $\mathrm{pH}$ diminution generally occurs as the time goes on during the reaction, which may course by the increase of released zinc ions when the sorbent was dispersed into the solution, and also by the buffering effect of $\mathrm{ZnAl}-\mathrm{EDTA}$. The optimum range of $\mathrm{pH}$ can be regarded as 4 to 6 based on the other previous studies [16], which is good for the liberation of EDTA ion during the reaction. The lower $\mathrm{pH}$ may lead to the increase of the zinc cation in the solution by the partial dissolution of layer. On the other hand, at higher $\mathrm{pH}$, the hydroxyl anions compete with EDTA for the precipitation of $\mathrm{Cd}(\mathrm{OH})_{2}$. Both the initial $\mathrm{pH}$ and the final $\mathrm{pH}$ were observed around 5-6 during the reaction in this work. It is indicated that the $\mathrm{pH}$ may not vary so much when the concentration of metal ion is low (100 ppb in this case) $[4,21,26,27]$, then the adsorption experiment was conducted without adjusting $\mathrm{pH}$ in this study.

\subsection{Adsorption Isotherms and Kinetic Models}

In order to verify the adsorbents as feasibility of process scale-up for more practical use, fitting the experimental data to the isotherm models and the kinetic models is significant.

Adsorption isotherms are commonly used to reflect the performance of adsorbents in adsorption processes. The adsorption data obtained for Cd(II) using ZnAl-EDTA were analyzed by Langmuir and Freundlich equations, and the results are shown in Fig. 4 and Fig. 5, respectively.

In this case, the Freundlich equation is more satisfactorily for $\mathrm{Cd}(\mathrm{II})$. The Freundlich isotherm model allows for several kinds of adsorption sites onto the adsorbent, and represents the adsorption data properly at low or intermediate concentration on heterogeneous surface. The correlation coefficients $\left(R^{2}\right)$ of Langmuir and Freundlich isotherm are shown in Table 2 along with other relevant parameters. $K_{\mathrm{F}}$ is

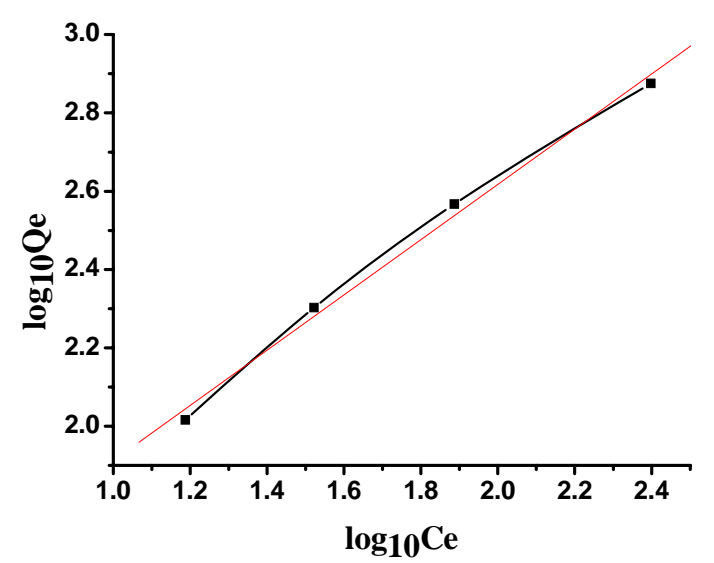

Fig. 4 Frendlich isotherm fitting for $\mathrm{Cd}(\mathrm{II})$ adsorption onto adsorbents. 


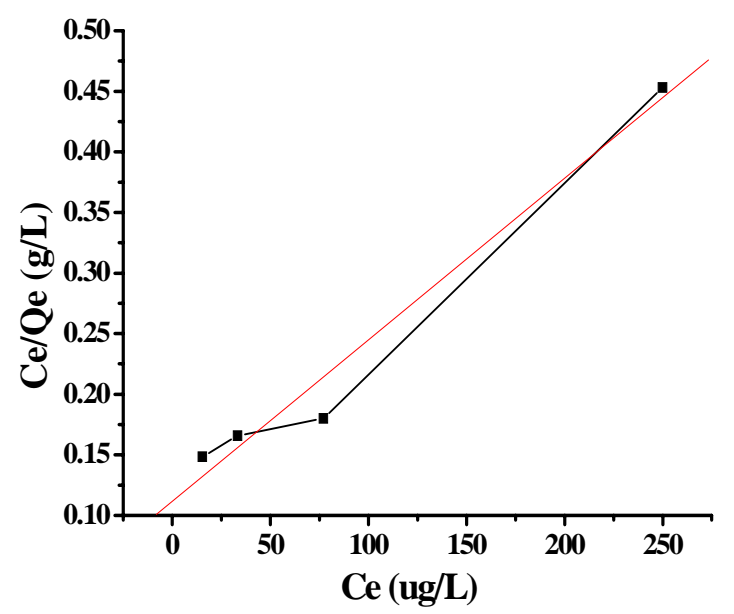

Fig. 5 Langmuir isotherm fitting for Cd(II) adsorption onto adsorbents.

a measure of adsorption capacity, and $1 / n$ refers to the adsorption intensity of the system. It is shown that $1 / n$ values between 0.1 and 1.0 refers to an interaction between exchange sites in the adsorbent and $\mathrm{Cd}(\mathrm{II})$ cations $[20,26,28,29]$. The $K_{\mathrm{F}}$ and $1 / n$ in Table 2 indicates the adsorption process is favorable.

The parameters of the kinetic models and the linear regression coefficients $\left(R^{2}\right)$ are listed in Table 3 . From Table 3, it is found that pseudo-second-order kinetic model fit the experimental data because $R^{2}$ value for pseudo-second-order kinetic model is comparatively large, whereas the value for pseudo-first-order kinetic model is fairly small. The linear plot of $t / q_{t}$ versus time $t$ for $\mathrm{Cd}(\mathrm{II})$ adsorption under the optimized experimental conditions is shown in Fig. 6. The $q_{e}$ value calculated from the pseudo-second-order models is very consistent with the experimental $q_{e}$ value $\left(q_{e \text { EXP }}\right)$.

\section{Conclusions}

Zn-Al LDHs intercalated with EDTA were synthesized by anion exchange reaction and characterized. The results from FT-IR etc. suggest that EDTA were intercalated into layered double hydroxide successfully. The decrease of $\mathrm{Zn} / \mathrm{Al}$ molar ratio suggests hydroxyl layer has a partial dissolution during that the reaction process.

The isotherm models such as Langmuir and Freundlich were used to analyze the adsorption data. The adsorption of Cd(II) by the ZnAl-EDTA was well fitted to Freundlich isotherms, which suggests that the adsorption occurred for several kinds of adsorption sites onto the adsorbent.

The kinetic studies of $\mathrm{Cd}(\mathrm{II})$ adsorption by the ZnAl-EDTA was analyzed using the pseudo-first order and pseudo-second order kinetic models, and it shows better fitting for the pseudo-second order model in this work.

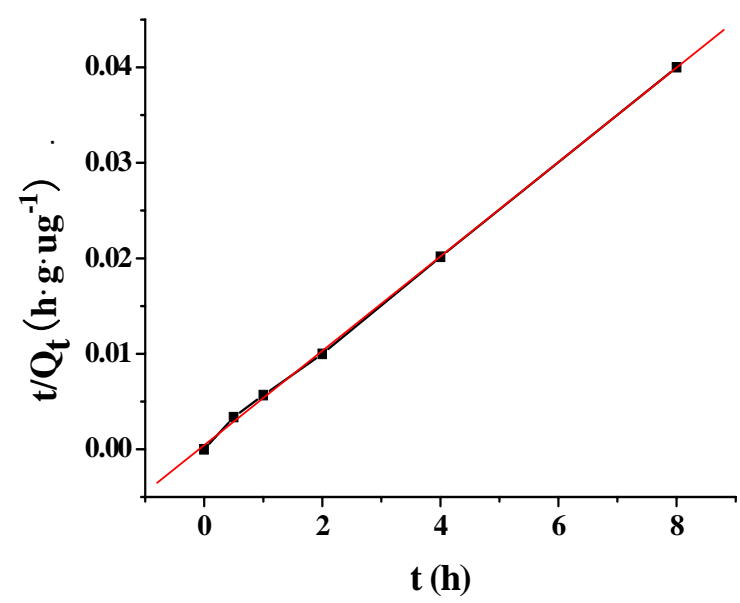

Fig. 6 The pseudo-second-order kinetic model for adsorbents.

Table 2 Coefficient of Langmuir and Freundlich isotherms for Cd(II).

\begin{tabular}{llllll}
\hline \multicolumn{3}{l}{ Freundlich isotherm } & \multicolumn{2}{c}{ Langmuir isotherm } \\
\hline$K_{F}\left(\mu \mathrm{g}^{1-1 / \mathrm{n}} \cdot \mathrm{g}^{-1} \cdot \mathrm{L}^{-1}\right)$ & $1 / n$ & $R^{2}$ & $K_{L}\left(\mathrm{~L}^{-1} \cdot \mu \mathrm{g}^{-1}\right)$ & $q_{\max }\left(\mu \mathrm{g} \cdot \mathrm{g}^{-1}\right)$ & $R^{2}$ \\
16.1 & 0.710 & 0.992 & 0.0150 & 730 & 0.982 \\
\hline
\end{tabular}

Table 3 The Kinetic fit parameters for Cd(II) adsorbed on LDHs.

\begin{tabular}{lllllll}
\hline \multicolumn{5}{l}{ Preudo-first-order } & \multicolumn{5}{l}{ Preudo-second-order } \\
\hline$q_{e}\left(\mu \mathrm{g} \cdot \mathrm{g}^{-1}\right)$ & $K_{l}\left(\mathrm{~h}^{-1}\right)$ & $R^{2}$ & $q_{e}\left(\mu \mathrm{g} \cdot \mathrm{g}^{-1}\right)$ & $K_{2}\left(\mathrm{~g} \cdot \mu \mathrm{g}^{-1} \cdot \mathrm{h}^{-1}\right)$ & $R^{2}$ & $q_{e E X P}\left(\mu \mathrm{g} \cdot \mathrm{g}^{-1}\right)$ \\
8.80 & -0.434 & 0.406 & 202 & 0.0568 & 0.998 & 200 \\
\hline
\end{tabular}


$\mathrm{Zn}$ (II) released in aqueous solution may affect the removal percentage (maximum $66.7 \%$, not shown) by competing with $\mathrm{Cd}(\mathrm{II})$, which may be attributable to the similar stability constants between chelated zinc and chelated cadmium. More detailed research about the stability of adsorbent will be needed.

The uptake process of heavy metal ions onto LDHs includes the chelation with EDTA and the precipitation. This complex mechanism enables EDTA intercalated LDHs to have high affinity for removing $\mathrm{Cd}(\mathrm{II})$. Based on the adsorption efficiency of this adsorbent, ZnAl-EDTA synthesized in this work can be an efficient adsorbent for heavy metal ions.

\section{Acknowledgments}

The present work was partially supported by a Grant-in-Aid for Scientific Research of the Japan Society for the Promotion of Science. The authors are grateful to Mr. M. Ohizumi of Office for Environment and Safety in Niigata University, Dr. E. Tayama of the Facility of Science and Dr. M. Teraguchi of the Facility of Engineering in Niigata University for permitting the use of ICP-AES, Elemental Analyzer and FT-IR, and for giving helpful advice in measurement.

\section{References}

[1] Xu, Y., and Zhang, F. 2006. "Experimental Research on Heavy Metal Wastewater Treatment with Dipropyl Dithiophosphate.” Journal of Hazardous Materials B 137: 1636-42.

[2] Gonzalez, M. A., Pavlovic, I., Rojas, R., and Barriga, C. 2014. "Removal of $\mathrm{Cu}^{2+}, \mathrm{Pb}^{2+}$ and $\mathrm{Cd}^{2+}$ by Layered Double Hydroxide-humate Hybrid. Sorbate and Sorbent Comparative Studies." Chemical Engineering Journal 254: 605-11.

[3] Jiao, Y., Grant, C. A., and Bailey, L. D. 2004. "Effects of Phosphorus and Zinc Fertilizer on Cadmium Uptake and Distribution in Flax and Durum Wheat." Journal of the Science of Food and Agriculture 84 (8): 777-85.

[4] Rojas, R. 2014. "Copper, Lead and Cadmium Removal by $\mathrm{Ca}$ Al Layered Double Hydroxides." Applied Clay Science 87: 254-9.
[5] Kameda, T., Saito, S., and Umetsu, Y. 2005. "Mg-A1 Layered Double Hydroxide Intercalated with Ethylene Diamine Tetraacetate Anion: Synthesis and Application to the Uptake of Heavy Metal Ions from an Aqueous Solution." Separation and Purification Technology 47: 20-6.

[6] Wang, L. J., Zhang, J., Liu, J. Z., He, H., Ying, M., Yu, J. W., Ma, Z. C., and Jiang, F. 2010. "Removal of Bromated Ion Using Powdered Activated Carbon." Journal of Environmental Sciences 22 (12): 1846-53.

[7] Hamdi, N., and Srasra, E. 2012. "Removal of Phosphate Ions from Aqueous Solution Using Tunisian Clays Minerals and Synthetic Zeolite." Journal of Environmental Sciences 4: 617-23.

[8] Arwidsson, Z., Elgh-Dalgren, K., Von Kronhelm, T., Sjoberg, R., Allard, B., and Van Hees, P. 2010. "Remediation of Heavy Metal Contaminated Soil washing Residues with Amino Polycarboxylic Acids." Journal of Hazardous Materials 173: 697-704.

[9] Jiao, F. P., Chen, X. Q., Liu, L., Hu, Z. D., Hu, Y. H., and Wang, Y. H. 2010. "Preparation and Characterization of $\mathrm{Mg}-\mathrm{Al} / \mathrm{Zn}-\mathrm{Al}$ Layered Double Hydroxides Intercalated with (+)-2,3-di(p-toluyl)-tartaric Acid." Journal of Molecular Structure 3: 152-7.

[10] Zhang, H., Zou, K., Guo, S. H., and Duan, X. 2006. "Nanostructural Drug-inorganic Clay Composites: Structure, Thermal Property and in Vitro Release of Captopril-intercalated Mg-Al-Layered Double Hydroxides." Journal of Solid State Chemistry 179: 1792-801.

[11] Pavlovic, I., Perez, M. R., Barriga, C., and Ulibarri, M. A. 2009. "Adsorption of $\mathrm{Cu}^{2+}, \mathrm{Cd}^{2+}$ and $\mathrm{Pb}^{2+}$ Ions by Layered Double Hydroxides Intercalated with the Chelating Agents Ethylene Diamine Tetraacetic Acid and Meso-2,3-dimercaptosuccinate." Applied Clay Science 43: $125-9$.

[12] Kameda, T., Takeuchi, H., and Yoshioka, T. 2011. "Ni-Al Layered Double Hydroxides Modified with Citrate, Malate, and Tartrate: Preparation by Coprecipitation and Uptake of $\mathrm{Cu}^{2+}$ from Aqueous Solution." Journal of Physics and Chemistry of Solids 72: 846-51.

[13] Zhang, S., Kano, N., and Imaizumi, H. 2014. “Adsorption of $\mathrm{Cu}(\mathrm{II}), \mathrm{Pb}(\mathrm{II})$ by Mg-Al-Layered Double Hydroxides (LDHs): Intercalated with the Chelating Agents EDTA and EDDS." Journal of Chemical Engineering of Japan 47 (4): $1-5$.

[14] Reichle, W. T. 1986. "Synthesis of Anionic Clay Minerals (Mixed Metal Hydroxides, Hydrotalcite)." Solid States Ionics 22: 135-41.

[15] Sato, T., Kato, K., Endo, T., and Shimada, M. 1986. "Preparation and Chemical Properties of Magnesium 
Aluminium Oxide Solid Solutions.” Reuctiuity of Solids 2: 253-60.

[16] Perez, M. R., Pavlovic, I., Barriga, C., Cornejo, J., Hermosín, M. C., and Ulibarri, M. A. 2006. "Uptake of $\mathrm{Cu}^{2+}, \mathrm{Cd}^{2+}$ and $\mathrm{Pb}^{2+}$ on $\mathrm{Zn}$-Al Layered Double Hydroxide Intercalated with EDTA." Applied Clay Science 32: 245-51.

[17] Liang, X. F., Hou, W. G., Xu, Y. M., Sun, G. H, Wang, L., Sun, Y., and Qin, X. 2010. "Sorption of Lead Ion by Layered Double Hydroxide Intercalated with Ethylene Diamine Tetraacetic Acid." Colloids and Surfaces A: Physicochem. Eng. Aspects 366: 50-7.

[18] Sui, M. H., Zhou, Y. F., Sheng, L., and Duan, B. B. 2012. "Adsorption of Norfloxacin in Aqueous Solution by Mg-Al-Layered Double Hydroxides with Variable Metal Composition and Interlayer Anions." Chemical Engineering Journal 210: 451-60.

[19] Gasser, M. S., and Aly, H. F. 2009. "Kinetic and Adsorption Mechanism of $\mathrm{Cu}(\mathrm{II})$ and $\mathrm{Pb}$ (II) on Prepared Nanoparticle Layered Double Hydroxide Intercalated with EDTA." Colloids and Surfaces A: Physicochem. Eng. Aspects 336: 167-73.

[20] Zhao, D. L., Sheng, G. D., Hu, J., Chen, C. L., and Wang, X. K. 2011. "The Adsorption of $\mathrm{Pb}(\mathrm{II})$ on $\mathrm{Mg}_{2} \mathrm{Al}$ Layered Double Hydroxide." Chemical Engineering Journal 171: $167-74$.

[21] Rojas, R., Perez, M. R., Erro, E. M., Ortiz, P. I., Ulibarri, M. A., and Giacomelli, C. E. 2009. "EDTA Modified LDHs as $\mathrm{Cu}^{2+}$ Scavengers: Removal Kinetics and Sorbent Stability." Journal of Colloid and Interface Science 331: 425-31.

[22] Rives, V. 2001. Layered Double Hydroxides: Present and
Future. ed. New York: Nova Sci. Pub. Inc.

[23] Parida, K. M., Baliarsingh, N., Sairam Patra, B., and Das, J. 2006. "Copper Phthalocyanine Immobilized $\mathrm{Zn} / \mathrm{Al}$ LDH as Photocatalyst under Solar Radiation for Decolorization of Methylene Blue." Journal of Molecular Catalysis A: Chemical 267: 202-8.

[24] Park, M., Choi, C. L., Seo, Y. J., Yeo, S. K., Choi, J., Komarneni, S., and Lee, J. H. 2007. "Reactions of $\mathrm{Cu}^{2+}$ and $\mathrm{Pb}^{2+}$ with $\mathrm{Mg} / \mathrm{Al}$ Layered Double Hydroxide." Applied Clay Science 37: 143-8.

[25] Cavani, F., Trifirb, F., and Vaccari, A. 1991. "Hydrotalcite Type Anionic Clays: Preparation, Properties and Applications." Catalysis Today 11: 173-301.

[26] Gonzalez, M. A., Pavlovic, I., and Barriga, C. 2015. " $\mathrm{Cu}(\mathrm{II}), \mathrm{Pb}(\mathrm{II})$ and $\mathrm{Cd}(\mathrm{II})$ Sorption on Different Layered Double Hydroxides. A Kinetic and Thermodynamic Study and Competing Factors." Chemical Engineering Journal 269: 221-8.

[27] Liang, X. F., Zang, Y. B., Xu, Y. Y., Tan, X., Hou, W. G., Wang, L., and Sun, Y. B. 2013. "Sorption of Metal Cations on Layered Double Hydroxides." Colloids and Surfaces A: Physicochem. Eng. Aspects 433: 122-31.

[28] Chitrakar, R., Tezuka, S., Sonoda, A., Sakane, K., Ooi, K., and Hirotsu, T. 2007. "Synthesis and Phosphate Uptake Behavior of $\mathrm{Zr}^{4+}$ Incorporated Mg-Al-Layered Double Hydroxides." Journal of Colloid and Interface Science 313: 53-63.

[29] Tan, X. L., Wang, X. K., Fang, M., and Chen, C. L. 2007. "Sorption and Desorption of Th(IV) on Nanoparticles of Anatase Studied by Batch and Spectroscopy Methods." Colloid Surf A 296: 109-16. 